\title{
Gefitinib inhibits malignant melanoma cells through the VEGF/AKT signaling pathway
}

\author{
XUEFENG WAN ${ }^{*}$, YALIN ZHU* ${ }^{*}$ LIJUAN ZHANG and WEI HOU \\ Department of Dermatology and Venereology, The First Affiliated Hospital of \\ Xinjiang Medical University, Urumqi, Xinjiang 830054, P.R. China
}

Received October 13, 2016; Accepted June 13, 2017

DOI: $10.3892 / \mathrm{mmr} .2018 .8728$

\begin{abstract}
Malignant melanoma (MM) is caused by melanophore cancerization in tissue pigmentation regions, leading to skin, mucous membrane, eye and central nervous system carcinogenesis. The incidence of MM has increased in previous years, and it has become the primary cause of skin cancer-associated mortality in developed countries. MM is characterized as highly malignant and readily metastasized, and has a poor prognosis. Targeting angiogenesis is an important method for MM treatment. As an important proangiogenic factor in tumor growth and metastasis, vascular endothelial growth factor (VEGF) can promote neovascularization and increase vascular permeability. Gefitinib is a novel drug targeting VEGF. The effect and mechanism of gefitinib on $\mathrm{MM}$ remain to be elucidated, and were investigated in the present study. The A375 MM cell line was used in the present study; it was cultured in vitro and divided into gefitinib groups (5 and $10 \mu \mathrm{M}$ ) and a control group. Cell proliferation was measured using an MTT assay and the activity of caspase-3 was assessed using a kit. Cell invasive ability was determined using a Transwell chamber. The mRNA and protein expression levels of VEGF and AKT were detected using reverse transcription-quantitative polymerase chain reaction and western blot analyses. Gefitinib significantly inhibited MM cell proliferation, enhanced the activity of caspase 3 and suppressed tumor cell invasion $(\mathrm{P}<0.05)$. In addition, gefitinib significantly downregulated the mRNA and protein expression levels of VEGF and AKT, and these changes were dose-dependent $(\mathrm{P}<0.05)$. Taken together, gefitinib suppressed
\end{abstract}

Correspondence to: Dr Yalin Zhu, Department of Dermatology and Venereology, The First Affiliated Hospital of Xinjiang Medical University, 137 Liyushannan Road, Urumqi, Xinjiang 830054, P.R. China

E-mail: yalinzhu123@sina.com

${ }^{*}$ Contributed equally

Key words: gefitinib, malignant melanoma, vascular endothelial growth factor, AKT, proliferation
MM cell proliferation and invasion in vitro by regulating the VEGF/AKT signaling pathway.

\section{Introduction}

Malignant melanoma (MM), primarily caused by melanophore cancerization and hyperplasia, can occur in the skin, mucous membranes and central nervous system $(1,2)$. MM is a common type of malignant tumor in dermatology with a high malignancy and incidence. The median survival rate of patients with $\mathrm{MM}$ is only 18 months, and it is the leading cause of skin malignant tumor-associated mortality around the world $(3,4)$. The occurrence of MM has ethnic and regional features, being higher in the European and American countries. It is the cause of skin cancer-associated mortality in developed countries $(5,6)$. In the Asian population, primary cutaneous melanoma accounts for $50-70 \%$ of cases, where the primary pathological type is entigo maligna melanoma, followed by superficial invasive melanoma and nodular MM (7,8). Previously, the incidence of MM was low in China; however, the incidence of MM has gradually increased following changes to lifestyle. MM is characterized as highly malignant and readily metastasized, and has a poor prognosis (9).

The pathogenetic mechanism of MM is complex and remains to be fully elucidated. Multiple factors are associated with the induction of MM, including genetics, physics, chemistry, family history and long-term sun exposure (10). Following detailed investigations of the mechanism, current treatment methods for MM include chemotherapy and molecular target therapy. The aim of molecular target therapy is to interpose MM proliferation and mutation from the molecular level $(11,12)$. Although multiple molecular anticancer drugs for MM have been examined, their curative effect remains poor. Tumor angiogenesis is important in the occurrence and development of MM; therefore, targeting angiogenesis is important for the treatment of MM (13). As an important proangiogenic factor of tumor growth and metastasis, VEGF can promote neovascularization and increase vascular permeability (14). Gefitnib is a novel target drug against VEGF (15). However, the effect and mechanism of gefitinib in MM remain to be fully elucidated. Therefore, the present study aimed to investigate the effect of gefitinib on MM cell proliferation and invasion, and the associated mechanism. 


\section{Materials and methods}

Main instruments and reagents. The MM A375 cell line was purchased from the American Type Culture Collection Cell Bank (ATCC; Mannasas, VA, USA). DMEM, FBS, and penicillin-streptomycin were obtained from Hyclone; GE Healthcare Life Sciences (Logan, UT, USA). Dimethyl sulfoxide and MTT powder were purchased from Gibco; Thermo Fisher Scientific, Inc. (Waltham, MA, USA). Enzyme-EDTA was from Sigma-Aldrich; Merck Miilipore (Darmstadt, Germany). The caspase-3 activity detection kit and PVDF membrane were from Pall Life Sciences (Ann Arbor, MI, USA). EDTA was purchased from Hyclone; GE Healthcare Life Sciences. The reagents associated with western blot analysis were from Beyotime Institute of Biotechnology (Haimen, China). ECL reagent was from GE Healthcare Life Sciences. Rabbit anti-human VEGF (cat. no. 2463) and AKT (cat. no. 4691) monoclonal antibodies, and mouse anti-rabbit horseradish peroxidase (HRP)-tagged IgG secondary antibody (cat. no. 5127) were from Cell Signaling Technology, Inc. (Danvers, MA, USA). The Transwell chamber was from Corning Inc. (Corning, NY, USA). The ABI 7700 Fast fluorescence quantitative PCR reaction apparatus was from Applied Biosystems; Thermo Fisher Scientific, Inc. The RNA extraction kit and reverse transcription kit were from Axygen Biosceiences (Union City, CA, USA). Other common reagents were purchased from Sangon Biotech Co., Ltd. (Shanghai, China). The Labsystem version 1.3.1 microplate reader was from Bio-Rad Laboratories, Inc. (Hercules, CA, USA).

MM A375 cell culture and grouping. The A375 cell line stored in liquid nitrogen was thawed in a $37^{\circ} \mathrm{C}$ water bath and centrifuged at $300 \mathrm{x}$ g for $3 \mathrm{~min}$ at room temperature. The cells were then resuspended in $1 \mathrm{ml}$ medium and cultured in a $50 \mathrm{ml}$ flask at $37^{\circ} \mathrm{C}$ and $5 \% \mathrm{CO}_{2}$ for $24-48 \mathrm{~h}$. The cells were passaged every 2-3 days and were used for experiments in the logarithmic phase at passages 2-8. The cells were divided into three groups, including the control, $5 \mu \mathrm{M}$ gefitinib group and $10 \mu \mathrm{M}$ gefitinib group. The cells in the treatment two groups were treated with gefitinib for $48 \mathrm{~h}$ at $37^{\circ} \mathrm{C}$.

MTT assay. The A375 cells in the logarithmic phase were seeded into 96 -well plate at $5 \times 10^{3} /$ well for $24 \mathrm{~h}$. The cells were divided into control and gefitinib groups with three replicates, which were cultured for $48 \mathrm{~h}$. Subsequently, the plate was treated with $20 \mu 15 \mathrm{~g} / 1 \mathrm{MTT}$ solution and incubated for $4 \mathrm{~h}$ at $37^{\circ} \mathrm{C}$. Following removal of the supernatant, $150 \mu 1$ DMSO was added to the plate for $10 \mathrm{~min}$ and read at $570 \mathrm{~nm}$ to calculate the proliferation rate.

Transwell assay. The Transwell chamber was coated with $50 \mathrm{mg} / 1 \mathrm{l}$ Matrigel at 1:5 for $24 \mathrm{~h}$ and then air dried at $4^{\circ} \mathrm{C}$. A total of $500 \mu 1$ DMEM containing 10\% FBS were added to the lower chamber, and $100 \mu \mathrm{l}$ tumor cell suspension in FBS-free medium was added to the upper chamber with three replicates. The cells in the control were cultured in a Transwell chamber without Matrigel. After $48 \mathrm{~h}$, the chamber was washed in PBS and fixed in ice ethanol. Following staining with crystal violet, the cells on the lower membrane were counted under a light microscope (BX43; Olympus
Corporation, Tokyo, Japan). All experiments were repeated three times.

Detection of caspase-3 activity. Caspase 3 activity was detected using a kit according to the manufacturer's instructions. The cells were digested in enzyme and centrifuged at $600 \mathrm{~g}$ and $4^{\circ} \mathrm{C}$ for $5 \mathrm{~min}$. The cells were then placed on ice for $15 \mathrm{~min}$ and centrifuged at $20,000 \mathrm{~g}$ and $4^{\circ} \mathrm{C}$ for $5 \mathrm{~min}$. Following the addition of $2 \mathrm{mM}$ Ac-DEVD-pNA, the sample was read at $405 \mathrm{~nm}$.

Reverse transcription-quantitative polymerase chain reaction (RT- $q P C R$ ) analysis. Total RNA was extracted from the A375 cells using TRIzol and reverse transcribed into cDNA. The primers used were designed by Primer 6.0 software (Premier Biosoft, Palo Alto, CA, USA) and synthetized by Invitrogen; Thermo Fisher Scientific, Inc. (Table I). qPCR was performed in a total volume of $20 \mu$, including $10 \mu$ l SYBR Green qPCR Super mix, $0.5 \mu \mathrm{l}$ forward primer $(10 \mu \mathrm{M}), 0.5 \mu \mathrm{l}$ reverse primer $(10 \mu \mathrm{M}), 5 \mu \mathrm{cDNA}$ and $4 \mu \mathrm{l}$ sterile water. The reaction conditions were as follows: $55^{\circ} \mathrm{C}$ for $1 \mathrm{~min}$, followed by 35 cycles of $92^{\circ} \mathrm{C}$ for $30 \mathrm{sec}, 58^{\circ} \mathrm{C}$ for $45 \mathrm{sec}$, and $72^{\circ} \mathrm{C}$ for $35 \mathrm{sec}$. GAPDH was used as internal reference. The $2^{-\Delta \Delta \mathrm{Cq}}$ method (16) was applied to calculate relative expression levels.

Western blot analysis. The cells were lysed in RIPA buffer (150 mM NaCL, $1 \%$ NP-40, 0.1\% SDS, $2 \mu \mathrm{g} / \mathrm{ml}$ aprotinin, $2 \mu \mathrm{g} / \mathrm{ml}$ leupeptin, $1 \mathrm{mM}$ PMSF, $1.5 \mathrm{mM}$ EDTA and $1 \mathrm{mM}$ NaVanadate) on ice for 15-30 min and ultrasonicated for $5 \mathrm{sec}$ four times to extract protein. Following centrifugation at $10,000 \mathrm{x} \mathrm{g}$ and $4^{\circ} \mathrm{C}$ for $15 \mathrm{~min}$, the protein was moved to a new Ep tube and store at $-20^{\circ} \mathrm{C}$. The protein was separated by $10 \%$ SDS-PAGE and transferred onto a PVDF membrane. Following blocking in 5\% skim milk for $2 \mathrm{~h}$, the membrane was incubated in VEGF primary antibody at 1:1,000 and AKT primary antibody at 1:2,000 overnight at $4^{\circ} \mathrm{C}$. The membrane was then incubated with secondary antibody at 1:2,000 for $30 \mathrm{~min}$ at room temperature and washed with PBST. Finally, the membrane was treated with chemiluminescent agent for $1 \mathrm{~min}$, and underwent X-ray imaging. The protein image processing system and Quantity One software version 4.6 (Bio-Rad Laboratories, Inc.) were used for data analysis. All experiments were repeated four times.

Statistical analysis. All statistical analyses were performed on SPSS 11.5 software (SPSS, Inc., Chicago, IL, USA). Measurement data are presented as the mean \pm standard deviation. One-way analysis of variance was used for comparison of means. $\mathrm{P}<0.05$ was considered to indicate a statistically significant difference.

\section{Results}

Effects of gefitinib on melanoma cell proliferation. An MTT assay was used to examine the effect of gefitinib on A375 cell proliferation. The results showed that gefitinib treatment for $48 \mathrm{~h}$ significantly suppressed A375 cell proliferation, compared with the control $(\mathrm{P}<0.05)$. Following an increase in dose, the tumor cell-suppressing effect was more marked $(\mathrm{P}<0.05 ;$ Fig. 1). These results suggested that gefitinib inhibited abnormal proliferation of the MM cells. 
Table I. Primer sequences.

\begin{tabular}{lll}
\hline Genes & \multicolumn{1}{c}{ Forward (5'-3') } & \multicolumn{1}{c}{ Reverse $\left(5^{\prime}-3^{\prime}\right)$} \\
\hline GADPH & AGTACCAGTCTGTTGCTGG & TAATAGACCCGGATGTCTGGT \\
VEGF & ATCCTTATCTCTGTGTGGAACTTTGTG & CTCCCTCTCAGCGCTCACAGCTTGCTG \\
AKT & TATCTCTCTGTCTCCCACAGAAGTC & TACTTACCTCGCATGGGGTAATTTGG \\
\hline
\end{tabular}

VEGF, vascular endothelial growth factor.

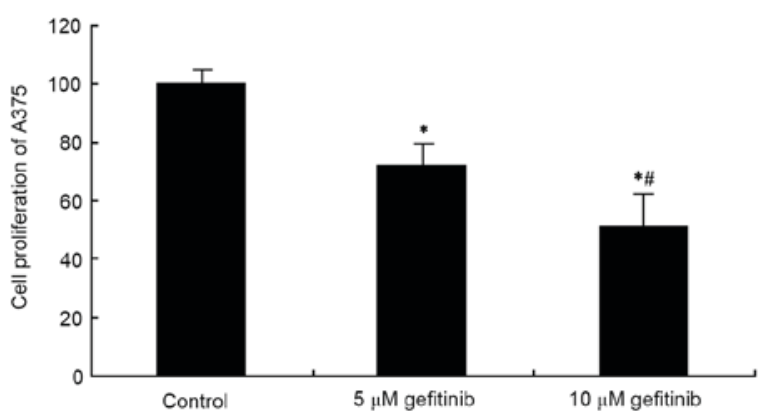

Figure 1. Effect of gefitinib on malignant melanoma cell proliferation ${ }^{*} \mathrm{P}<0.05$, compared with the control; ${ }^{*} \mathrm{P}<0.05$, compared with $5 \mu \mathrm{M}$ gefitinib.

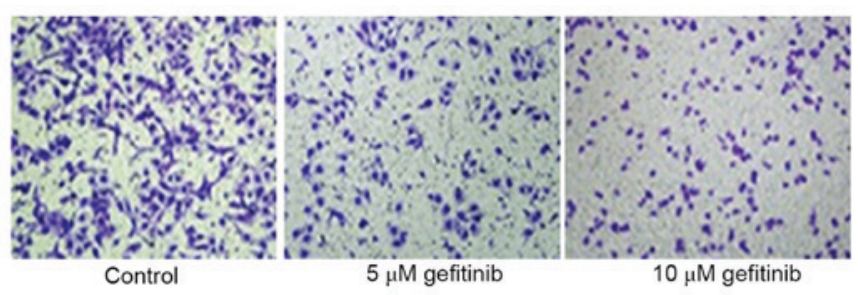

Figure 2. Effect of gefitinib on malignant melanoma cell invasion. Images of stained cells in each group (x40 magnification).

Effects of gefitinib on MM cell invasion. A Transwell assay was used to determine the effect of effect on the invasive ability of A375 cells. It was revealed that gefitinib treatment for $48 \mathrm{~h}$ markedly inhibited A375 cell invasion, compared with that in the control $(\mathrm{P}<0.05)$. Following an increase in dose, gefitinib had a more marked suppressive effect on tumor cell invasion $(\mathrm{P}<0.05$; Figs. 2 and 3$)$. These results indicated that gefitinib affected MM cell invasive ability.

Effect of gefitinib on the activity of caspase-3 in MM cells. A caspase 3 activity detection kit was used to measure the effect of gefitinib on the activity of caspase- 3 in the A375 cells. The results demonstrated that gefitinib treatment for $48 \mathrm{~h}$ significantly increased the activity of caspase- 3 in the A375 cells $(\mathrm{P}<0.05)$. Following an increase of dose, gefitinib exerted a more marked promoting effect on the activity of caspase-3 $(\mathrm{P}<0.05$; Fig. 4). These results suggested that gefitinib promoted MM cell apoptosis by enhancing the activity of caspase-3.

Effects of gefitinib on the mRNA expression of VEGF and AKT in MM cells. RT-qPCR analysis was used to determine the effect of gefitinib on the mRNA expression of VEGF and AKT mRNA in A375 cells. The results showed that gefitinib

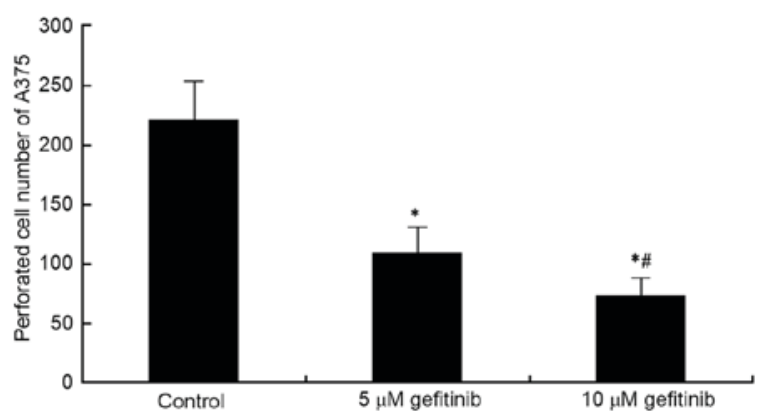

Figure 3. Effect of gefitinib on malignant melanoma cell invasion. ${ }^{*} \mathrm{P}<0.05$, compared with the control; ${ }^{\#} \mathrm{P}<0.05$, compared with $5 \mu \mathrm{M}$ gefitinib.

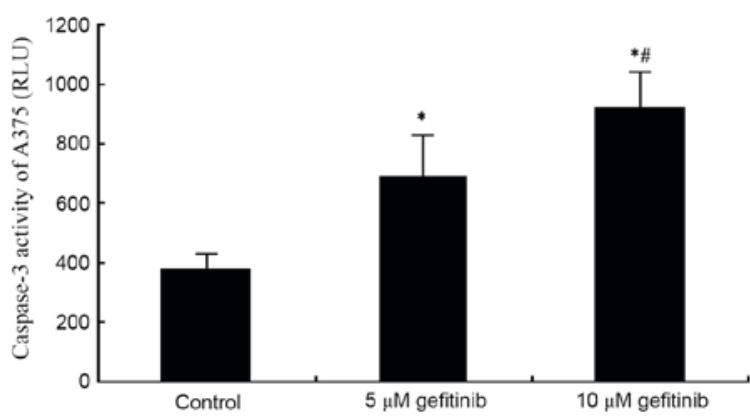

Figure 4. Effect of gefitinib on the activity of caspase-3 in malignant melanoma cells. ${ }^{*} \mathrm{P}<0.05$, compared with the control; ${ }^{\#} \mathrm{P}<0.05$, compared with $5 \mu \mathrm{M}$ gefitinib.

treatment for $48 \mathrm{~h}$ markedly decreased the mRNA expression of VEGF in the A375 cells $(\mathrm{P}<0.05)$. Following an increase in dose, gefitinib exerted a higher suppressive effect on VEGF $(\mathrm{P}<0.05$; Fig. 5). In addition, gefitinib treatment for $48 \mathrm{~h}$ significantly reduced the mRNA expression of AKT in the A375 cells $(\mathrm{P}<0.05)$. An increase in dose also resulted in an increased suppressive effect on AKT ( $<<0.05$; Fig. 6).

Effect of gefitinib on the protein expression of VEGF in MM cells. Western blot analysis was performed to detect the effect of gefitinib on the protein expression of VEGF in A375 cells. It was found that, similar to the mRNA expression of VEGF, gefitinib treatment for $48 \mathrm{~h}$ weakened the protein expression of VEGF in A375 cells $(\mathrm{P}<0.05)$. Following dose elevation, gefitinib exerted a higher suppressive effect on VEGF ( $\mathrm{P}<0.05$; Figs. 7 and 8$)$.

Effect of gefitinib on the protein expression of AKT in MM cells. Western blot analysis was used to determine the effect of gefitinib on the protein level of AKT in A375 cells. It 


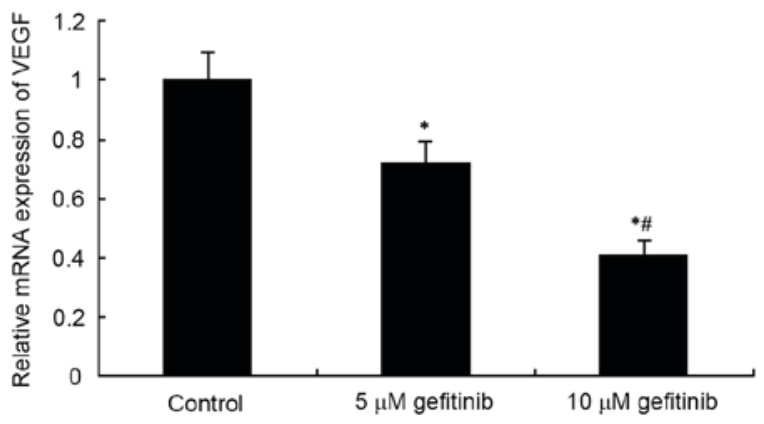

Figure 5. Effect of gefitinib on the mRNA expression of VEGF in malignant melanoma cells. " $\mathrm{P}<0.05$, compared with the control; ${ }^{~} \mathrm{P}<0.05$, compared with $5 \mu \mathrm{M}$ gefitinib. VEGF, vascular endothelial growth factor.

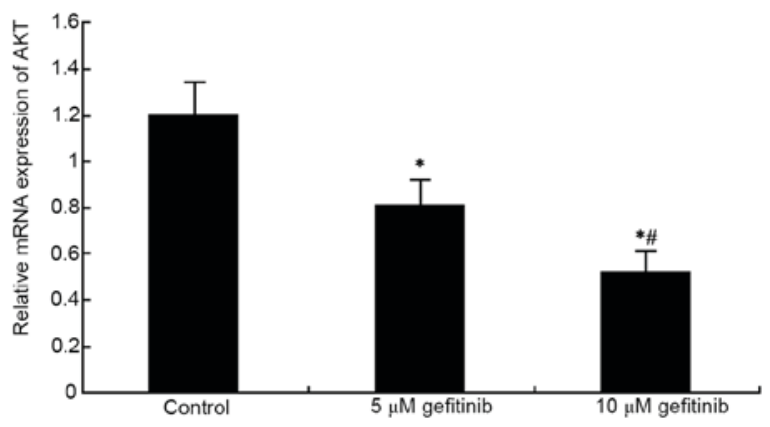

Figure 6. Effect of gefitinib on the mRNA expression of AKT in malignant melanoma cells. ${ }^{~} \mathrm{P}<0.05$, compared with the control; ${ }^{~} \mathrm{P}<0.05$, compared with $5 \mu \mathrm{M}$ gefitinib.

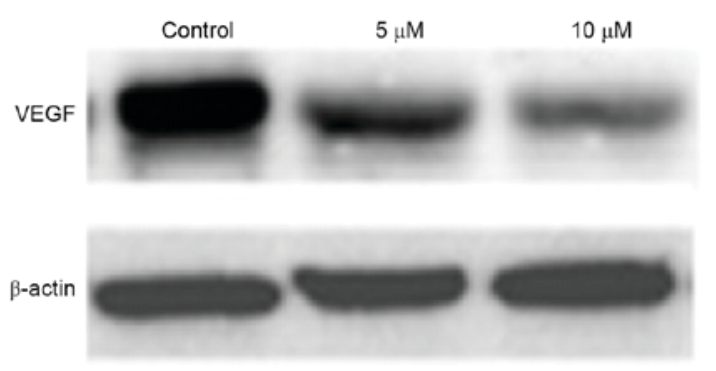

Figure 7. Effect of gefitinib on the protein expression of VEGF in malignant melanoma cells. Images show representative blots. VEGF, vascular endothelial growth factor.

was found that, similar to the mRNA expression of AKT, gefitinib treatment for $48 \mathrm{~h}$ decreased the protein expression of AKT in the A375 cells $(\mathrm{P}<0.05)$. Following dose elevation, gefitinib exerted a higher suppressive effect on AKT $(\mathrm{P}<0.05$; Figs. 9 and 10).

\section{Discussion}

The incidence of MM has gradually increased over time. Due to its lack of apparent symptoms in the early stage and its ability to metastasize, the majority of patients present with metastasis at diagnosis, leading to poor surgical outcome. In addition, chemotherapy drug resistance leads to MM treatment inefficiency (17). The present study showed that molecular target drugs have certain curative effects on MM.

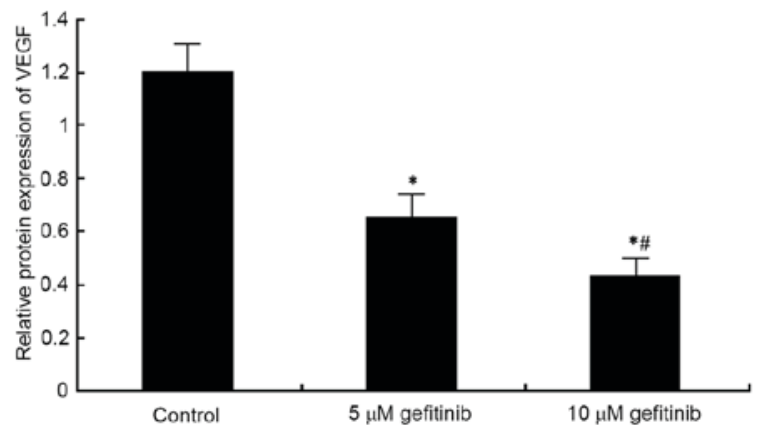

Figure 8. Effect of gefitinib on the protein expression of VEGF in malignant melanoma cells. "P<0.05, compared with the control; ${ }^{*} \mathrm{P}<0.05$, compared with $5 \mu \mathrm{M}$ gefitinib. VEGF, vascular endothelial growth factor.

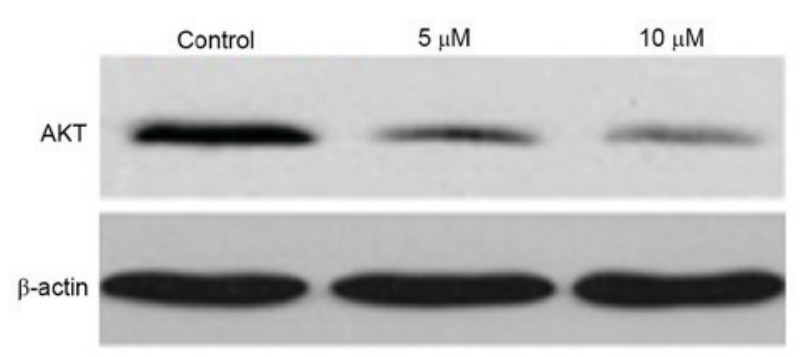

Figure 9. Effect of gefitinib on the protein expression of AKT in malignant melanoma cells. Images show representative blots.

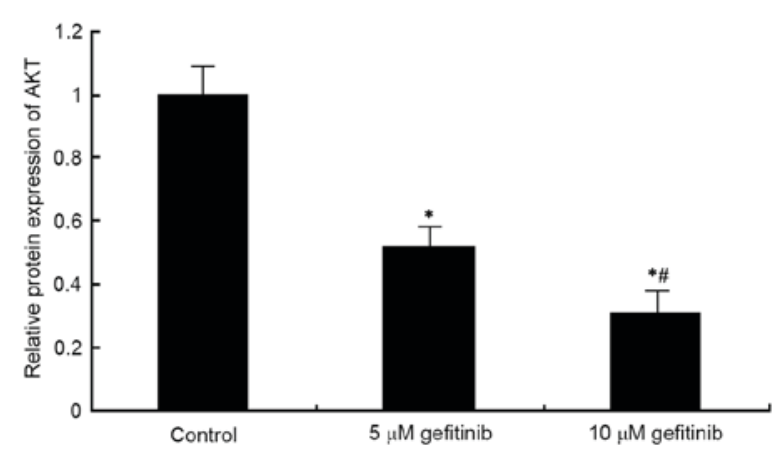

Figure 10. Effect of gefitinib on the protein expression of AKT in malignant melanoma cells. ${ }^{*} \mathrm{P}<0.05$, compared with the control; ${ }^{\prime \prime} \mathrm{P}<0.05$, compared with $5 \mu \mathrm{M}$ gefitinib.

Therefore, identifying suitable molecular target drugs to inhibit MM-associated pathways is likely to improve the survival rates and prognosis of patients with MM (18).

As one of the most important proangiogenic factors, VEGF is expressed in endothelial cells. It can promote vascular endothelial cell proliferation, differentiation, migration and movement, and form vessel structures by enhancing blood vessel permeability and degrading extracellular matrix (19). VEGF can promote neovascularization in tumorigenesis (20). The binding of VEGF to VEGF receptor, synergized with angiogenin-2, can facilitate lymphatic vessel hyperplasia surrounding the tumor to ensure that new capillaries can provide nutrition for the tumor and promote tumor metastasis (21). It has been shown that the protein kinase AKT is an important molecule involved in various biological behaviors of cells; for example, the overexpression of AKT promotes MM 
metastasis (22). In the present study, MM cells were treated with gefitinib targeting VEGF, and its effect and mechanism were analyzed. The results showed that gefitinib suppressed MM cell proliferation and inhibited cell invasive ability in a dose-dependent manner. Gefitinib promoted tumor cell apoptosis by enhancing the activity of caspase-3. Analysis of the mechanism confirmed that gefitinib suppressed the mRNA and protein expression of VEGF and AKT, suggesting that gefitinib may reduce the occurrence and development of MM through the VEGF/AKT pathway.

In conclusion, the present study confirmed that gefitinib suppressed MM cell proliferation and invasion in vitro through regulating the VEGF/AKT signaling pathway. These results indicate a potential molecular target and theoretical basis for the treatment of MM.

\section{References}

1. Whiteman DC, Green AC and Olsen CM: The growing burden of invasive melanoma: Projections of incidence rates and numbers of new cases in six susceptible populations through 2031. J Invest Dermatol 136: 1161-1171, 2016.

2. Soura E, Eliades PJ, Shannon K, Stratigos AJ and Tsao H: Hereditary melanoma: Update on syndromes and management: Emerging melanoma cancer complexes and genetic counseling. J Am Acad Dermatol 74: 411-420, 2016.

3. Chen H, Cai Y, Liu Y, He J, Hu Y, Xiao Q, Hu W and Ding K: Incidence, surgical treatment, and prognosis of anorectal melanoma from 1973 to 2011: A population-based SEER analysis. Medicine (Baltimore) 95: e2770, 2016.

4. Carter JH, Deddens JA, Spaulding NR IV, Lucas D, Colligan BM, Lewis TG, Hawkins E, Jones J, Pemberton JO, Douglass LE and Graff JR: Phosphorylation of eIF4E serine 209 is associated with tumour progression and reduced survival in malignant melanoma. Br J Cancer 114: 444-453, 2016.

5. Oba J, Nakahara T, Hashimoto-Hachiya A, Liu M, Abe T, Hagihara A, Yokomizo T and Furue M: CD10-equipped melanoma cells acquire highly potent tumorigenic activity: A plausible explanation of their significance for a poor prognosis. PLoS One 11: e0149285, 2016.

6. Soura E, Eliades PJ, Shannon K, Stratigos AJ and Tsao H: Hereditary melanoma: Update on syndromes and management: Genetics of familial atypical multiple mole melanoma syndrome. J Am Acad Dermatol 74: 395-407, 2016.

7. $\mathrm{Xu} \mathrm{X}, \mathrm{Cao} \mathrm{Z}$ and $\mathrm{Zhu} \mathrm{H}$ : Capsule endoscopy in the diagnosis of an exophytic gastrointestinal stromal tumor in the small intestine of a young adult woman: A case report. Mol Clin Oncol 4: 268-270, 2016.

8. Khoja L, Atenafu EG, Ye Q, Gedye C, Chappell M, Hogg D, Butler MO and Joshua AM: Real-world efficacy, toxicity and clinical management of ipilimumab treatment in metastatic melanoma. Oncol Lett 11: 1581-1585, 2016.

9. Ferreira AK, Pasqualoto KF, Kruyt FA, Palace-Berl F, Azevedo RA, Turra KM, Rodrigues CP, Ferreira AC, Salomón MA, de Sá Junior PL, et al: BFD-22 a new potential inhibitor of BRAF inhibits the metastasis of B16F10 melanoma cells and simultaneously increased the tumor immunogenicity. Toxicol Appl Pharmacol 295: 56-67, 2016.
10. You Z, Zhou Y, Guo Y, Chen W, Chen S and Wang X: Activating transcription factor 2 expression mediates cell proliferation and is associated with poor prognosis in human non-small cell lung carcinoma. Oncol Lett 11: 760-766, 2016.

11. Wang C, Chen YW, Zhang L, Gong XG, Zhou Y and Shang DJ: Melanoma cell surface-expressed phosphatidylserine as a therapeutic target for cationic anticancer peptide, temporin-1CEa. J Drug Target 24: 548-556, 2016

12. Ogawara K, Shiraishi T, Araki T, Watanabe T, Ono T and Higaki K: Efficient anti-tumor effect of photodynamic treatment with polymeric nanoparticles composed of polyethylene glycol and polylactic acid block copolymer encapsulating hydrophobic porphyrin derivative. Eur J Pharm Sci 82: 154-160, 2016.

13. Zhao X, Sun B, Liu Y, Zhang D, Liu Z, Zhao X, Gu Q, Han C, Dong $\mathrm{X}$, Che N, et al: Linearly patterned programmed cell necrosis induced by chronic hypoxia plays a role in melanoma angiogenesis. J Cancer 7: 22-31, 2016.

14. Lai YW, Wang SW, Chang CH, Liu SC, Chen YJ, Chi CW, Chiu LP, Chen SS, Chiu AW and Chung CH: Butein inhibits metastatic behavior in mouse melanoma cells through VEGF expression and translation-dependent signaling pathway regulation. BMC Complement Altern Med 15: 445, 2015.

15. Amin DN, Bielenberg DR, Lifshits E, Heymach JV and Klagsbrun M: Targeting EGFR activity in blood vessels is sufficient to inhibit tumor growth and is accompanied by an increase in VEGFR-2 dependence in tumor endothelial cells. Microvasc Res 76: 15-22, 2008.

16. Livak KJ and Schmittgen TD: Analysis of relative gene expression data using real-time quantitative PCR and the 2(-Delta Delta $\mathrm{C}(\mathrm{T})$ ) method. Methods 25: 402-408, 2001.

17. Wheatley K, Wilson JS, Gaunt P and Marsden JR: Surgical excision margins in primary cutaneous melanoma: A meta-analysis and Bayesian probability evaluation. Cancer Treat Rev 42: 73-81, 2016.

18. Gershenwald JE and Guy GP Jr: Stemming the rising incidence of melanoma: Calling prevention to action. J Natl Cancer Inst 108: djv381, 2015.

19. Zhang ZQ, Han YZ, Nian Q, Chen G, Cui SQ and Wang XY: Tumor invasiveness, not lymphangiogenesis, is correlated with lymph node metastasis and unfavorable prognosis in young breast cancer patients ( $\leq 35$ years). PLoS One 10: e0144376, 2015.

20. Naruse T, Yanamoto S, Yamada SI, Takahashi H, Matsushita Y, Imayama N, Ikeda $\mathrm{H}$, Shiraishi $\mathrm{T}$, Fujita S, Ikeda $\mathrm{T}$, et al: Immunohistochemical study of vascular endothelial growth factor-C/vascular endothelial growth factor receptor-3 expression in oral tongue squamous cell carcinoma: Correlation with the induction of lymphangiogenesis. Oncol Lett 10: 2027-2034, 2015.

21. Wang L, Li HG, Wen JM, Peng TS, Zeng H and Wang LY: Expression of CD44v3, erythropoietin and VEGF-C in gastric adenocarcinomas: Correlations with clinicopathological features. Tumori 100: 321-327, 2014.

22. Cho JH, Robinson JP, Arave RA, Burnett WJ, Kircher DA, Chen G, Davies MA, Grossmann AH, VanBrocklin MW, McMahon M and Holmen SL: AKT1 activation promotes development of melanoma metastases. Cell Rep 13: 898-905, 2015. 